\title{
Feasibility in assessing the dipped rail joint defects through dynamic response of heavy haul locomotive
}

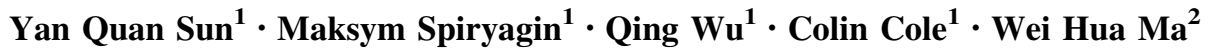

Received: 10 January 2017/Revised: 19 January 2018/Accepted: 23 January 2018/Published online: 5 March 2018

(C) The Author(s) 2018. This article is an open access publication

\begin{abstract}
The feasibility of monitoring the dipped rail joint defects has been theoretically investigated by simulating a locomotive-mounted acceleration system negotiating several types of dipped rail defects. Initially, a comprehensive locomotive-track model was developed using the multi-body dynamics approach. In this model, the locomotive car-body, bogie frames, wheelsets and driving motors are considered as rigid bodies; track modelling was also taken into account. A quantitative relationship between the characteristics (peak-peak values) of the axle box accelerations and the rail defects was determined through simulations. Therefore, the proposed approach, which combines defect analysis and comparisons with theoretical results, will enhance the ability for long-term monitoring and assessment of track systems and provides more informed preventative track maintenance strategies.
\end{abstract}

Keywords Axle box accelerations - Track monitoring · Dipped rail defects · Simulations

\section{Introduction}

The continual increase in wagon axle load, train length and speed in worldwide heavy haul railways has increased pressure on railway track operators to improve the capacity of their track system. Track damage and wheel and rail

Yan Quan Sun

y.q.sun@cqu.edu.au

1 Centre for Railway Engineering, Central Queensland University, Rockhampton, QLD, Australia

2 State Key Laboratory of Traction Power, Southwest Jiaotong University, Chengdu 610031, China defects appear more often than ever before. Short-wavelength wheel and rail defects such as wheel flats, squats on the rail top surface, rail welds with poor finishing quality, insulated rail joints, rail corrugations cause large dynamic contact forces at the wheel-rail interface, leading to fast deterioration of the track.

The development of squat defects has become a major concern in railway systems throughout the world. The findings of extensive field investigations into squat and related rail defects covering the Sydney metropolitan and interurban areas are reported [1]. The results of grinding rail evidencing squats and the measures proposed to reduce the potential for further squat development are also reported.

Rail joints are a weak component in railway tracks because of large impacts caused by wheel-rail contact forces. Every train passage contributes to the deterioration of rail joints, causing visible (e.g. battered rails) and less obvious (e.g. loose bolts) damage. Vehicle-borne monitoring systems may be used to automatically detect and assess the tightness condition of bolts at rail joints [2]. The monitoring method was developed based on field axle box acceleration measurements.

Aluminothermic welding of rails is widely used within the railway industry for in-track welding during re-railing operations and defect removal [3]. The process suffers from variable quality in finished welds due to inherent limitations in the field. Under high axle load conditions, the recent failures in aluminothermic welds represent one of the main risks for a catastrophic derailment and a major limitation to further increases in axle loads. Improved rail welding and track maintenance practices would be required to meet the performance demands of higher axle loads.

Despite substantial improvements in rail material development and in the quality of non-destructive inspection techniques, together with implementation of specifically 
tailored rail grinding strategies and other measures in order to guarantee safe service, fatigue crack propagation and fracture is still of great concern as emphasised by the present special issue [4]. Rails, as the core of the railway system, are subjected to very high service loads and harsh environmental conditions. Since any potential rail breakage includes the risk of catastrophic derailment of vehicles, it is of paramount importance to avoid such a scenario.

Condition monitoring of track and rail is seen as a significant contributor in preventing delays to trains and derailments of vehicles, thus achieving an improvement on the capacity of railway systems. Early detection and assessment of track defects are very important for timely maintenance. A more cost-effective approach is to estimate these short-wavelength defects using a small number of robust sensors such as rail vehicle axle box-mounted accelerometers. An attempt to determine a quantitative relationship between the characteristics of the accelerations and the track defects, axle box acceleration at a squat and a thermite weld were simulated through finite element modelling [5]. The simulated magnitude and frequency results of axle box acceleration at squats agreed with measurements. Furthermore, an automatic detection algorithm for squats using axle box acceleration measurements on trains was developed [6], which was based on wavelet spectrum analysis. The method can determine the squat locations, is sensitive to small rail surface defects and allows the detection of squats in their initial stages.

It was reported [7] that an online rail deformation monitoring system could be implemented on a moving train to obtain timely reports of any rail deformation beyond the threshold. This system was based on an effective algorithm for detecting rail deformation using three acceleration sensors mounted on the train. The proposed method can distinguish between vibrations due to track deformation from those caused by the motion of the train. Monitoring track defects on a periodic basis enables the network rail managers to apply proactive measures to limit further rail damage. The measurement methods for rail corrugation with particular regard to the analysis tools employed for evaluating the thresholds of acceptability in relation to an Italian tramway transport system are presented [8].

It is necessary to conduct theoretical simulations in order to determine the characteristics of the short-wavelength irregularities based on the AK track recording car's raw acceleration and processed displacement data [9]. A VAMPIRE generated vehicle model and a detailed threedimensional vehicle-track system dynamics model called CRE-3D VTSD - have been used to simulate the AK car wheel-rail dynamic behaviours as it passes through the short-wavelength defects.

A technique utilising accelerometer measurements taken on standard operating bogies was accepted as a quick track condition inspection of a subway [10] with a particular focus on short-pitch rail corrugation. A diagnostic tool, based on the wavelet transform, was able to detect and to quantify the wheel-flat defect of a test train [11] at various speeds and can accurately measure the train speed. Only one accelerometer was required to provide results in real time.

Rail damage detection exploiting ultrasonic wave propagation phenomena $(\mathrm{P}, \mathrm{S}$, Rayleigh and guided-wave velocities) identifies the presence of damage to the rail structure by discrepancies in the expected wave transmission paths [12]. The approach presented used a time-frequency coherence function for the identification of the returning guided waves reflected back to the sensors by the damage surfaces. It is suggested in [13] that the frequency range $(40-80 \mathrm{kHz})$ best supports guided waves in rails.

An approach for enhancing the assessment of vertical track geometry quality and rail surface roughness by means of train-track interaction simulation and wavelength content analysis is presented in [14]. Potential benefits of improving conventional track geometry inspection methods are demonstrated with numerical examples, in which defects of wavelength $0.5-2 \mathrm{~m}$ are highlighted as a cause of high dynamic wheel-rail interaction forces. By using a wavelength weighting for measured rail roughness, an improved way of analysing rail roughness data is also presented [14]. This improves track and rail condition assessments and allows the track engineer to better monitor the track condition.

Early detection and assessment of track short-wavelength defects are very important for planning timely track maintenance and preventing vehicle derailments. In this paper, a new approach is suggested using accelerometers mounted on a locomotive's bogie frames (or axle boxes) to estimate the dipped rail defects including squats on rail top surface, rail welds with poor finishing quality, insulated rail joints, etc. The advantage of locomotive componentmounted sensors lies in the following aspects: (1) Locomotive weight basically remains unchanged during operations. (2) The sensor signals can easily be shown in the cabin, providing the driver with real time monitoring.

First, a comprehensive locomotive-track model is generated using a multi-body dynamics approach with GENSYS software, which is a tool for modelling vehicles running on rails (but in its design GENSYS is a general multi purpose software package for modelling mechanical, electrical and/or mathematical problems). In the locomotive model [15-17], the car-body, bogie frames, wheelsets and driving motors are considered as rigid bodies; detailed modelling of the supporting track structure is also considered. Second, quantitative relationships between the characteristics of the bogie frame or axle box accelerations and the rail defects are determined through simulations. Finally, defect analysis is combined and compared with historical data. The proposed approach will enhance the 
ability for more regular detailed monitoring and assessment of the track system, allowing the implementation of more informed and proactive track maintenance strategies.

\section{Rail dipped defect measurements and modelling}

\subsection{Short-wavelength defect measurements}

Track defect measurements were taken on the Illawarra Line located between 80.140 and $80.212 \mathrm{~km}$ from Sydney. It was found that there were a number of small rail top

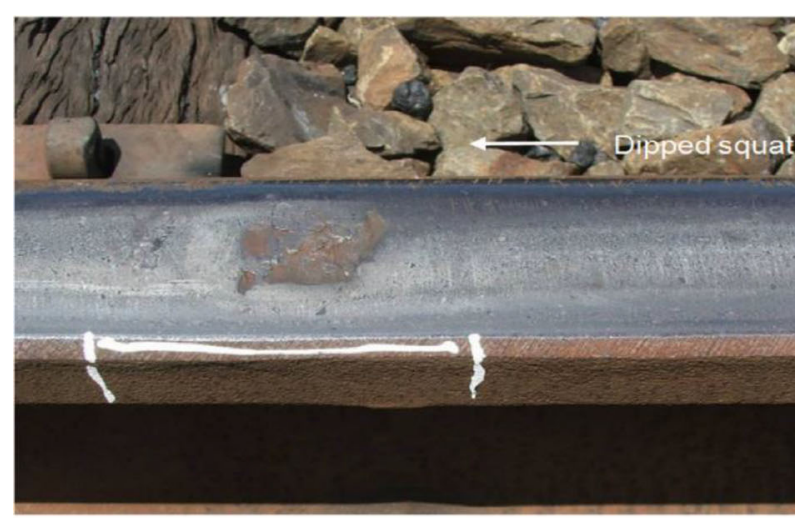

(a)

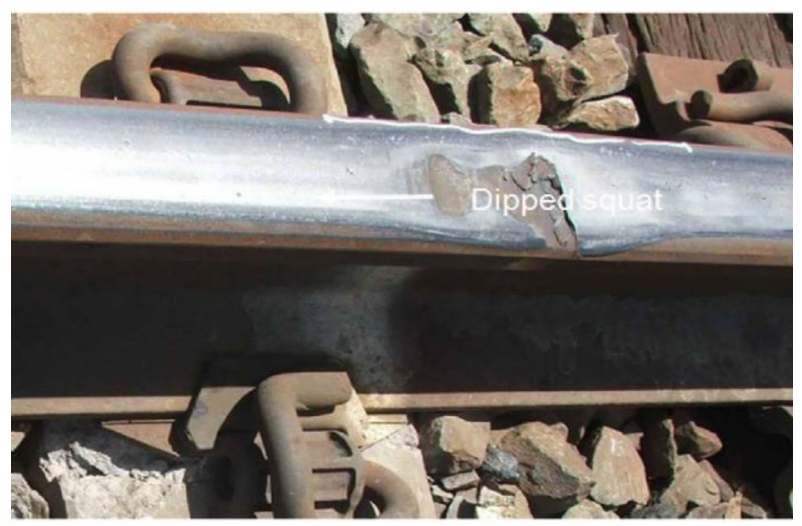

(b)

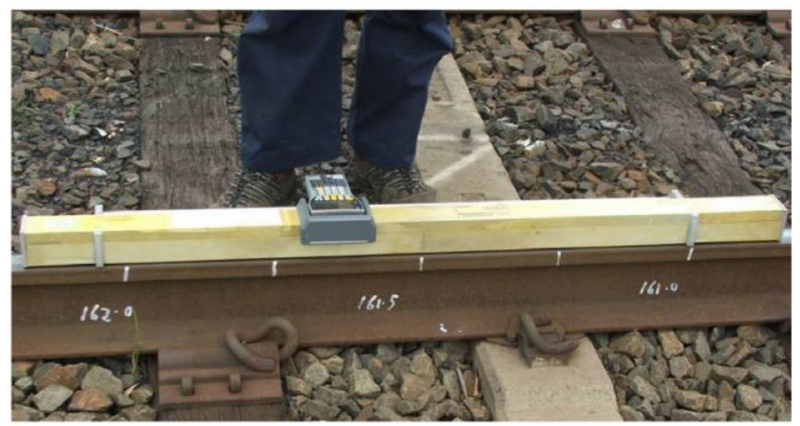

(c)

Fig. 1 Field site defects and measurement. a Squat at $80.159 \mathrm{~km}$ up rail. b Squat at $80.184 \mathrm{~km}$ up rail. c Dip gauge defects throughout the site associated with dipped welds, squats and top defects due to fouled ballast.

The measurements of dip profiles from a 1-m longitudinal chord were taken using a Metalelectro R2Srail surface scanner (dip gauge), as shown in Fig. 1c. This instrument provides vertical deviations from the chord at 2$\mathrm{mm}$ intervals with a specified accuracy of $\pm 10 \mu \mathrm{m}$. The longitudinal profiles of the short-wavelength defects shown in Fig. 1 $a$ and $b$ were measured using this dip gauge, and the measured results are shown in Fig. $2 a$ and $b$, respectively.

Other measurement results for the short-wavelength defects using a $300-\mathrm{mm}$ straight edge are set out in Table 1. A micrometer gauge attached to the straight edge provided vertical displacements from the centre of the straight edge. Measurements were taken in the centre of the rail.

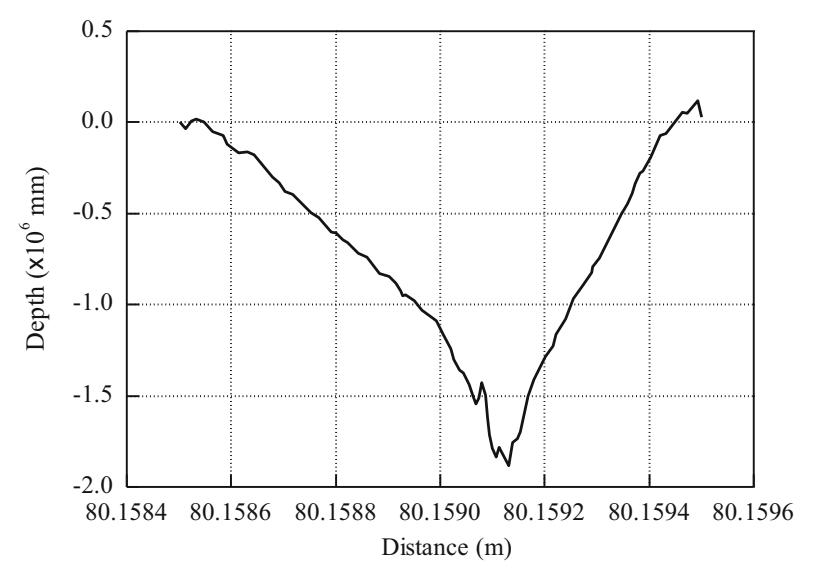

(a)

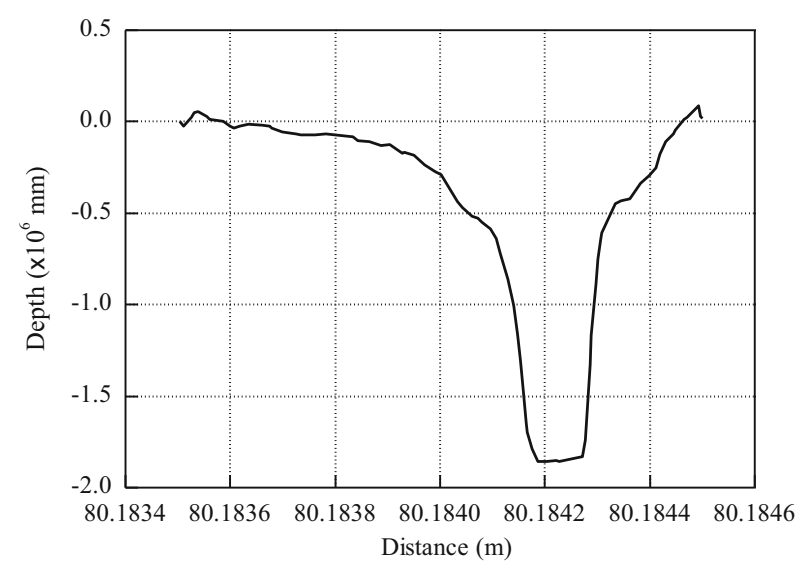

(b)

Fig. 2 Dip measurement profiles. a Dipped squat at $80.159 \mathrm{~km}$ up rail. b Dipped squat at $80.184 \mathrm{~km}$ up rail 
Table 1 Results from 300-mm straight edge gauge

\begin{tabular}{llc}
\hline Location $(\mathrm{km})$ & Observed feature & $\begin{array}{l}\text { Measured dip using 300-mm straight } \\
\text { edge }\end{array}$ \\
\hline $80.151,750$ right rail & Centre of thermite weld, $55 \mathrm{~mm}$ long & $0.6 \mathrm{~mm} \mathrm{dip}$ \\
$80.151,810$ left rail & Centre of thermite weld, $50 \mathrm{~mm}$ long & $1.0 \mathrm{~mm} \mathrm{dip}$ \\
$80.158,120$ left rail & Centre of thermite weld, $40 \mathrm{~mm}$ long & $1.8 \mathrm{~mm} \mathrm{dip}$ \\
$\begin{array}{l}80.159,045 \text { to } 80.159,130 \\
\text { right rail }\end{array}$ & 1 severe squat with spall about $50 \mathrm{~mm}$ long & $2.0 \mathrm{~mm} \mathrm{dip}$ \\
$\begin{array}{l}80.184,070 \text { to } 80.184,290 \\
\text { right rail }\end{array}$ & $\begin{array}{l}1 \text { very severe squat with spall about } 80 \mathrm{~mm} \text { long where concrete sleeper is } \\
\text { broken and rail dipped }\end{array}$ & $2.5 \mathrm{~mm}$ dip, right rail. $1.8 \mathrm{~mm}$ dip, \\
\hline
\end{tabular}

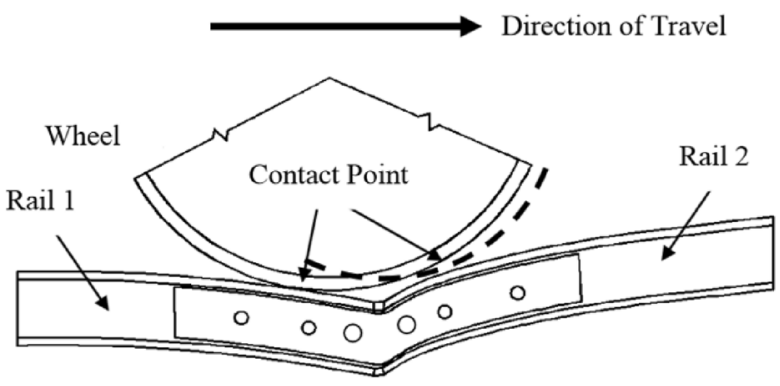

(a)

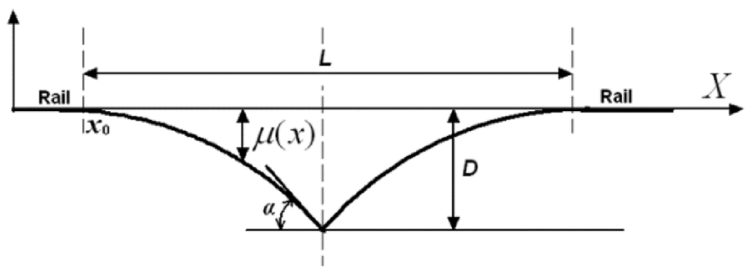

(b)

Fig. 3 Dipped rail defect modelling. a Dipped joint [20]. b Dipped rail defect model geometry

\subsection{Dipped rail defects and modelling}

Usually, a dipped rail joint defect (as shown in Fig. 3a) can be modelled as illustrated in Fig. $3 \mathrm{~b}$ and expressed mathematically by Eq. (1) [18-20]. Based on the measurements of squats shown in Fig. 2, it is thought [21] that typical squat defects can be also modelled using Eq. (1).

In Fig. $3 b, L$ is the dip length (m), $D$ is the dip depth $(\mathrm{mm})$, and $\alpha$ is the dip angle (rad). The rail joint dip can be expressed as

$\mu(x)= \begin{cases}-D\left[1-\cos \left(2 \pi \frac{x-x_{0}}{2 L}\right)\right], & x_{0} \leq x<x_{0}+L / 2, \\ -D\left[1+\cos \left(2 \pi \frac{x-x_{0}}{2 L}\right)\right], & x_{0}+L / 2 \leq x \leq x_{0}+L, \\ 0, & x>x_{0}+L .\end{cases}$
From Eq. (1), the relationship between the dip angle $\alpha$ and the dip length $L$ and depth $D$ can be approximately expressed as

$$
\alpha \approx \frac{D}{L} \pi
$$

\section{Detailed locomotive modelling}

To allow detailed simulation of accelerations for a locomotive under traction, the comprehensive locomotive-track model is created using the GENSYS Multi-Body Simulation (MBS) software. The modelled locomotive has a CoCo wheel arrangement, meaning that the car-body is connected to two three-axle bogies with each axle being independently driven by its own traction motor as shown in Fig. 4.

The locomotive model consists of twenty-one rigid bodies; one car-body, two bogie frames, six wheelsets, six motor housings and six motor rotors. Bogies are the conventional 'rigid' type where the wheelsets and traction motor assemblies are connected to a rigid frame, with the axles given some side play so they could shift laterally in low radii curves. Each bogie has a central pin to allow bogie rotation in curves and transfer of longitudinal force between the bogies and car-body. Total locomotive mass is $134 \mathrm{t}[22,23]$.

Brief descriptions of suspension elements in the modelled rigid bogie are given below.

\subsection{Secondary suspension elements}

- Rubber springs (linear) Each bogie has three rubber springs that the car-body rests on, with the inner spring being equivalent to both outer springs (twice the stiffness and vertical preload). Compressive stiffness must be high to support car-body weight, whilst low shear stiffness allows bogie (yaw) rotation in curves. 


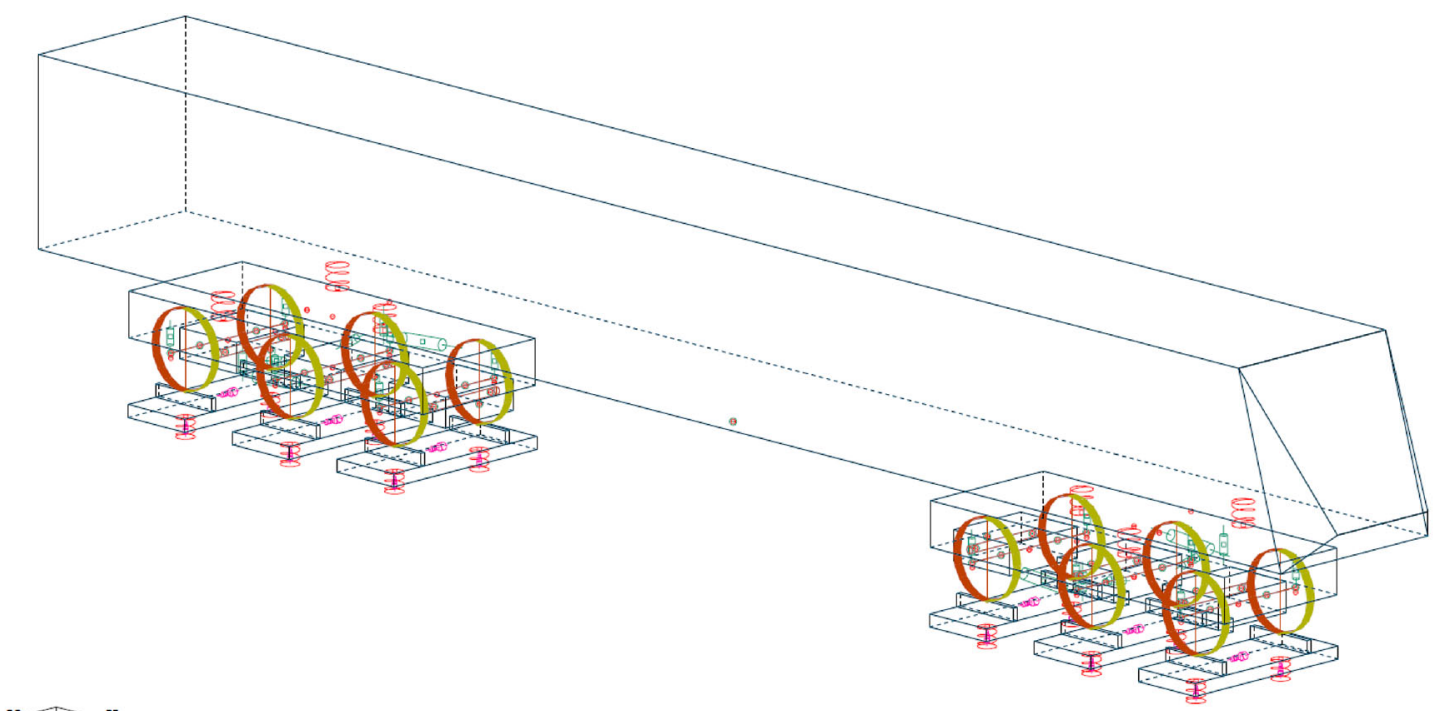

$T_{z} x$

(a)

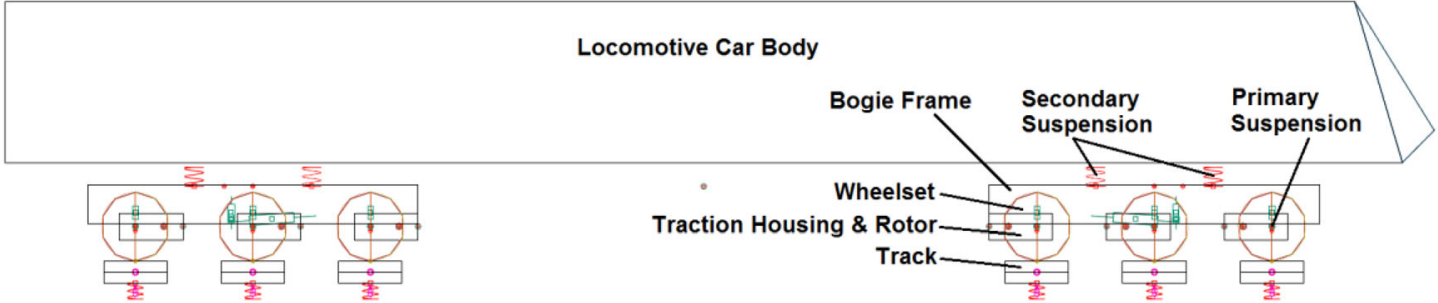

(b)

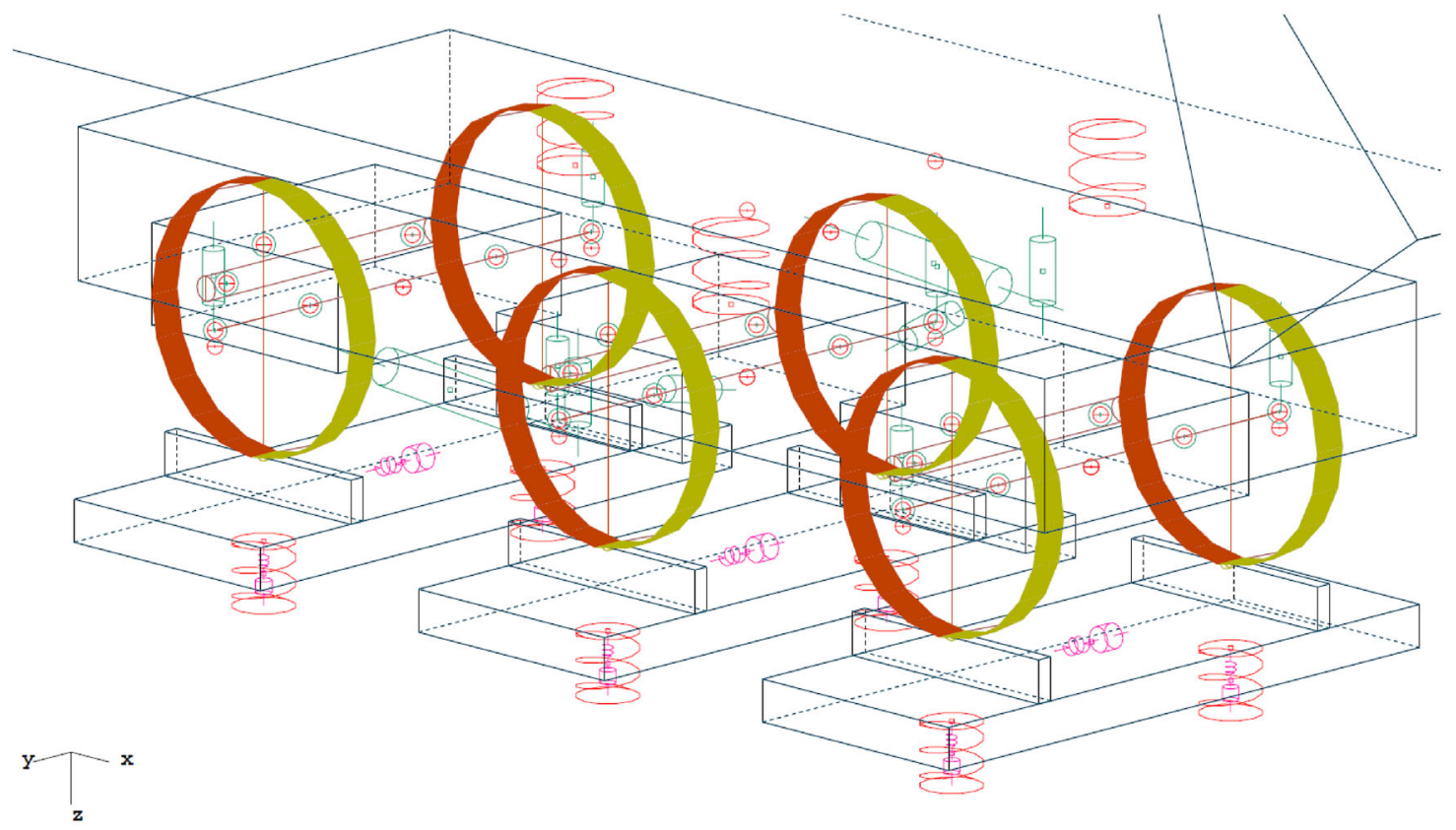

(c)

Fig. 4 Detailed locomotive and track models. a Locomotive model. b Side view of locomotive model. c Bogie and track model 
- Yaw viscous dampers These nonlinear blow-off dampers limit relative yaw between the bogie frames and car-body. In conjunction with the lateral viscous dampers, they help to control bogie hunting.

- Lateral viscous dampers (linear) Assist with controlling bogie hunting but have little effect on limiting relative yaw between the bogie frames and car-body.

- Lateral bumpstops Limit relative bogie displacements in the lateral direction at the bogie frame centre, with $60 \mathrm{~mm}$ of side play ( $30 \mathrm{~mm}$ left/right from centre).

- Vertical bumpstops Limit relative bogie displacements in the vertical direction. The left and right sides of the bogie frame allow $50 \mathrm{~mm}$ of vertical travel $(25 \mathrm{~mm}$ up/down from rest position).

- Bogie pivot pin Transfers tractive effort (longitudinal) and cornering (lateral) forces from the bogie to the carbody. These are modelled with two nonlinear springs constrained to move in the longitudinal and lateral directions, respectively, with $4 \mathrm{~mm}$ of travel $( \pm 2 \mathrm{~mm}$ from centre).

\subsection{Primary suspension elements}

Elements in the primary suspension, except for bumpstops, were assumed to be linear.

- Axle box springs (linear) Modelled as single springs, with parallel dampers positioned at the ends of wheelsets. Similar to the rubber springs in the secondary suspension, they have high compressive stiffness to support the car-body and bogie frame, but are soft in shear to allow lateral and longitudinal wheelset movement.

- Vertical viscous dampers (linear) Provide additional damping to help control vertical wheelset movements in response to track irregularities. These are only fitted to the lead and end axles in a bogie.

- Longitudinal bumpstops Limit relative wheelset displacements in the longitudinal direction at the wheelset centres, with $10 \mathrm{~mm}$ of longitudinal travel $(5 \mathrm{~mm}$ front/ back from centre).

- Lateral bumpstops Located in the same positions as longitudinal bumpstops (one per wheelset); $22 \mathrm{~mm}$ of travel (11 mm left/right from centre) for the lead and end axles, whilst mid-axles have $60 \mathrm{~mm}(30 \mathrm{~mm}$ left/ right). Stiffness characteristics also differ between lead/ end and mid-axle bumpstops.

- Vertical bumpstops Limit relative wheelset displacements in the vertical direction on the left and right sides of wheelsets (where the axle boxes would be on a realworld locomotive), with $50 \mathrm{~mm}$ of vertical travel ( $25 \mathrm{~mm}$ up/down from rest position).

\subsection{Track model}

Rails are modelled as separate weightless elements placed under each wheel, which could be connected with up to three wheel-rail contact points (i.e. cp1, cp2 and cp3). Each contact point is assumed to have linear stiffness and damping acting normal to the contacting wheel-rail surfaces. The two rails under each wheelset are connected to a body representing the track (sleepers) with lateral and vertical stiffness and damping elements. The track bodies have mass and are allowed to move in the lateral and vertical directions and rotate in yaw, giving 3 degrees of freedom (DOFs). These are, in turn, connected to the ground with a series of stiffness-damping elements in the lateral direction and two pairs of stiffness and a series of vertical stiffness-damping elements for the right and left sides of the track, respectively. The connections between the track and the ground include:

- Two vertical coil spring elements.

- Two vertical dampers and one lateral damper.

\subsection{Wheel-rail contact model}

Rails are modelled as separate massless elements under each wheel. The wheel and rail interface can be connected with up to three contact points, as shown in Fig. 5. Each contact point is assumed to have a linear stiffness element acting normal to the wheel-rail contact surfaces. Through each linear spring element, the normal wheel-rail contact force can be calculated. For the tangent creep force at each wheel-rail contact point, its calculation is completed in a lookup table based on Kalker creep theory. Finally, the resultant normal contact and tangent creep forces can be determined for these three contact points.

\section{Simulations}

In order to prove the effectiveness of a locomotive model, an example is available in [24], in which experiment data with the primary objective of verifying a model developed for rail joint defects were reported. The total angle of the dipped rail joint used in the experiment was $0.02 \mathrm{rad}$ on both rails at the same location. The dynamic response was calculated when a wagon travelling at a speed of $48.7 \mathrm{~km} / \mathrm{h}$ passed through this dipped rail joint. Figure 6a shows the contact forces obtained from the experimental data and the simulation [24] and compared with a simulation using the 3D WTSD model [25]. Figure $6 \mathrm{~b}$ and $\mathrm{c}$ shows time histories of the wheel-rail normal contact force for the middle wheelset of the leading bogie by the GENSYS locomotive model after the very limited data available [24] were used. 


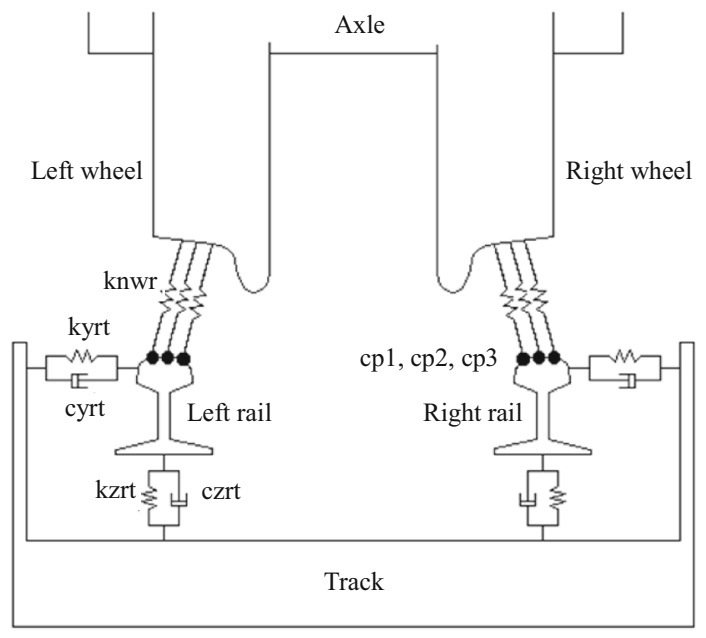

Fig. 5 Wheel-rail contact. knwr represents the wheel-rail contact stiffness, kyrt the lateral stiffness coefficient between rail and track, cyrt the lateral damping coefficient between rail and track, $k z r t$ the vertical stiffness coefficient between rail and track, and czrt the vertical damping coefficient between rail and track

The magnitude of the peak force agrees with the experimental and calculated data provided in [24].

In the comparison of Fig. 6a with c, although the magnitudes of the peak force agree well with each other, the variation curve of Fig. $6 \mathrm{c}$ is some different to that shown in Fig. 6a. The main reason is that the accurately repeated prediction of wheel-rail contact force is very difficult because it is related to many factors such as the contact stiffness, the rail defect shape and depth, the vehicle weight and suspensions, the track parameters. In addition, it is very difficult to get all the physical parameters from the experiment into the simulations. Besides, it is well known that a multi-rigid-body model such as the current model in this paper may not be enough for the simulations of midand high-frequency of rail vehicle-tracks. The possible solutions to the high-frequency interactions of rail vehicletrack system due to short rail defects can be the use of detailed FE wheel-rail model, the flexible vehicle-track model, etc.

The locomotive model can be considered to be reliable because it was generated based on a GENSYS rail vehicle model, which was compared and validated during Manchester Benchmark tests [26].

In our previous investigation on track forces [21, 27], the relationship between the track $P_{2}$ force [18], the wheelset axle box vertical acceleration, the dip lengths and the dip angles was simulated and is shown in Fig. 7.

The $P_{2}$ force was calculated at the nominal maximum speed and nominal gross mass of the vehicle in accordance with Eq. (3), which was developed by Jenkins et al. [18]:

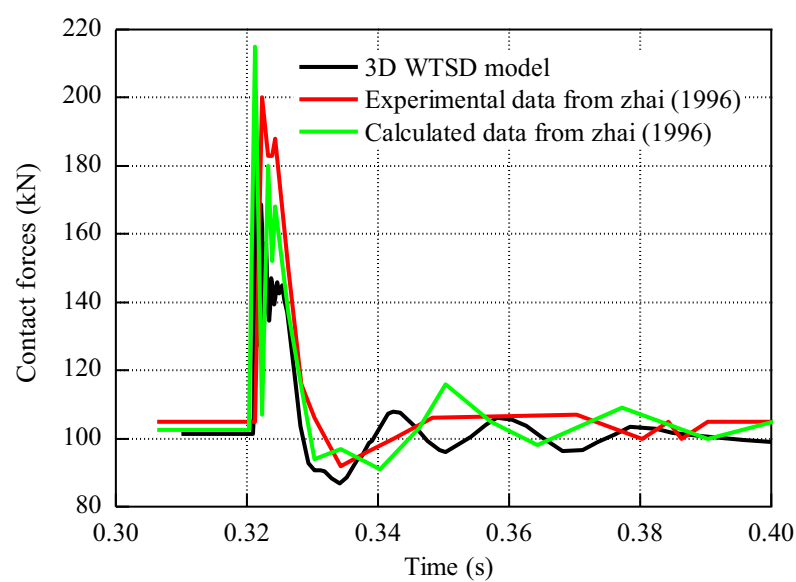

(a)

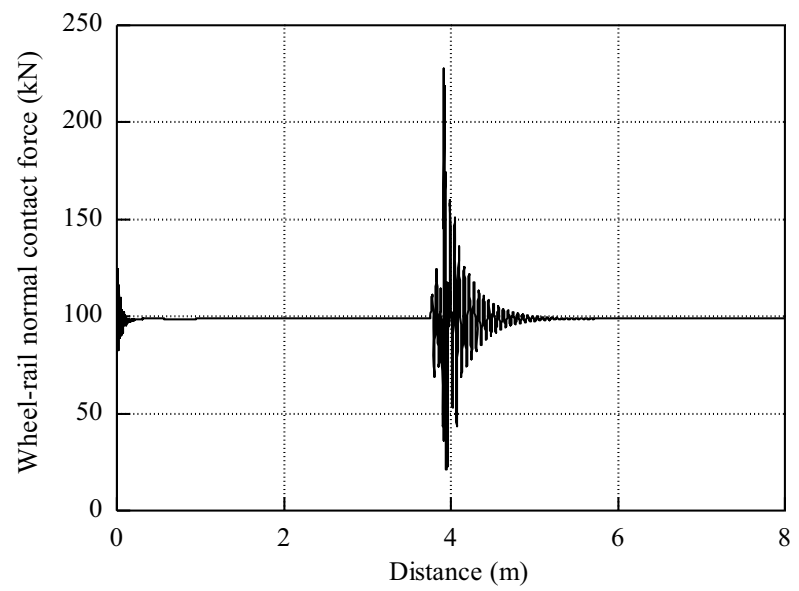

(b)

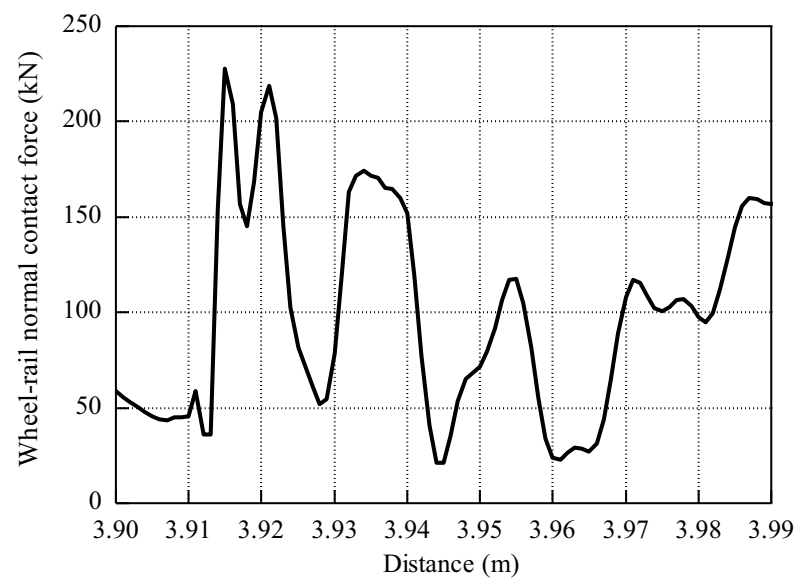

(c)

Fig. 6 Simulation comparison. a Published data. b GENSYS simulation. c Zoom of Fig. 1b 

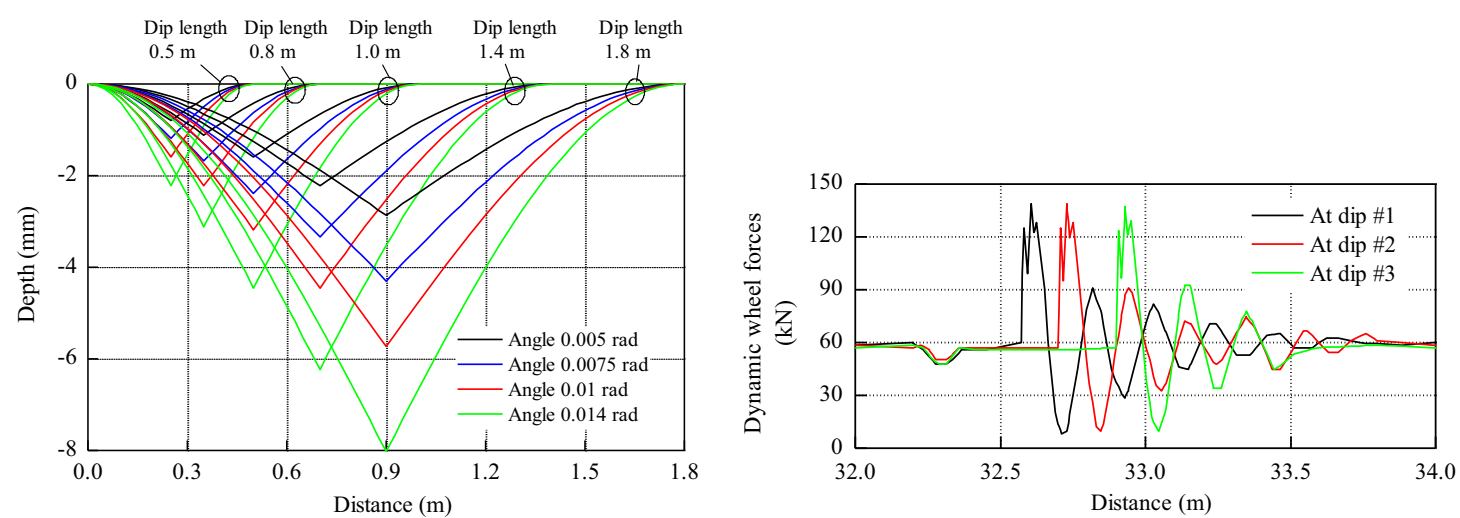

(a)
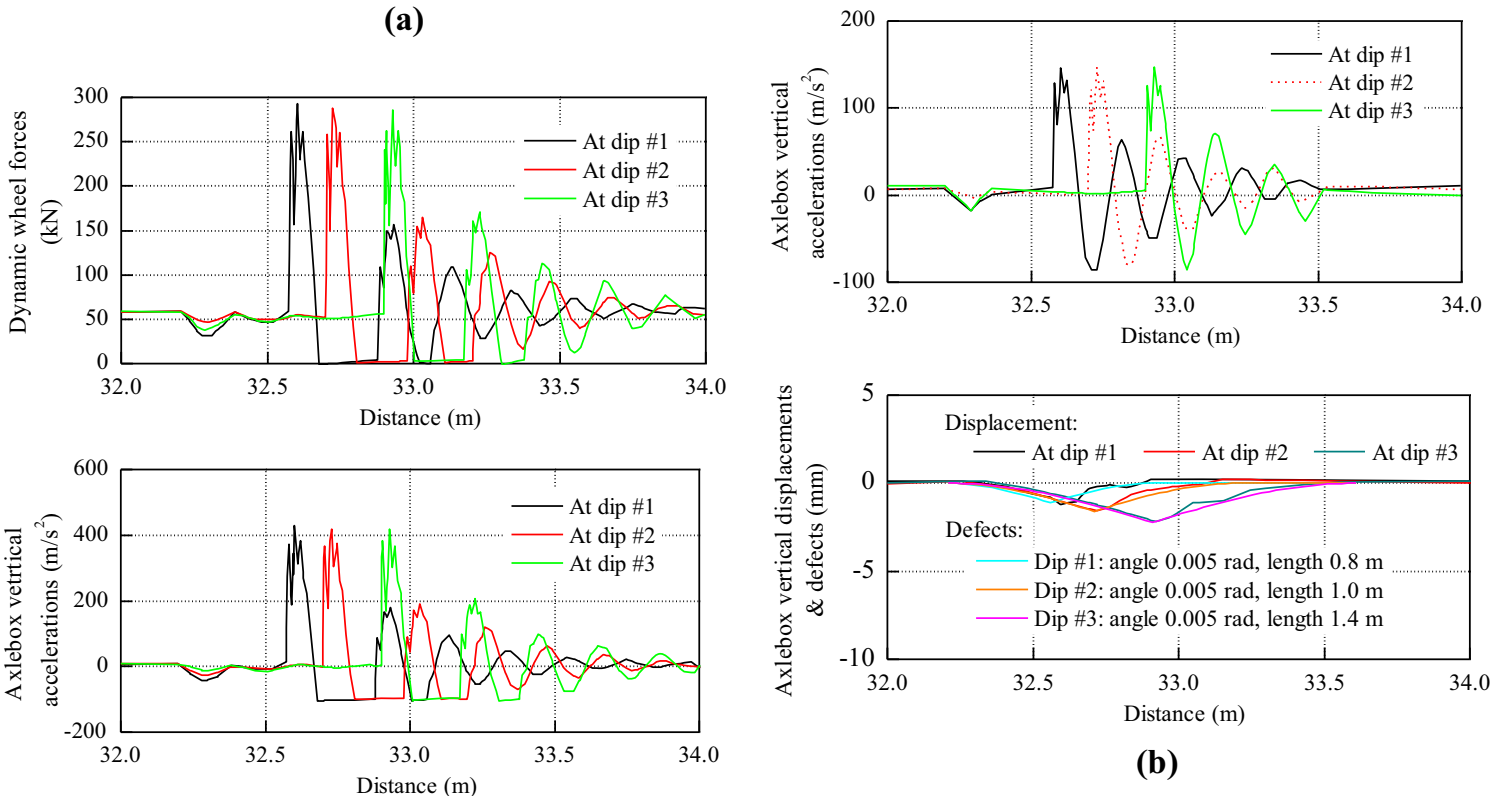

(b)

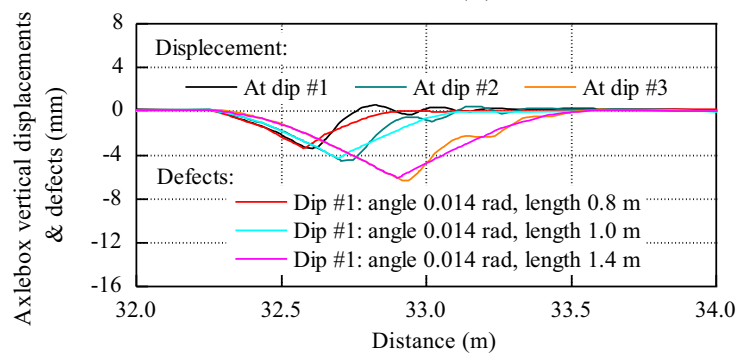

(c)

Fig. 7 Simulation results in the previous research [29]. a Weld joint dips with various angles and lengths. b $\alpha=0.005$ rad. c $\alpha=0.014$ rad

$$
\begin{aligned}
P_{2}= & P_{0}+2 \alpha V\left[\frac{M_{\mathrm{u}}}{M_{\mathrm{u}}+M_{\mathrm{t}}}\right]^{0.5} \times\left[1-\frac{C_{\mathrm{t}} \pi}{4\left[K_{\mathrm{t}}\left(M_{\mathrm{u}}+M_{\mathrm{t}}\right)\right]^{0.5}}\right] \\
& \times\left[K_{\mathrm{t}} M_{\mathrm{u}}\right]^{0.5}
\end{aligned}
$$

where $P_{0}$ is the static wheel load $(\mathrm{kN}), M_{\mathrm{u}}$ is the rail vehicle unsprung mass $(\mathrm{kg}), 2 \alpha$ is the total joint dip angle $(\mathrm{rad}), V$ is the vehicle speed $(\mathrm{m} / \mathrm{s}), K_{\mathrm{t}}$ is the equivalent track stiffness $(\mathrm{MN} / \mathrm{m})$ (nominally $109 \mathrm{MN} / \mathrm{m}), C_{\mathrm{t}}$ is the equivalent track damping $(\mathrm{kNs} / \mathrm{m})$ (nominally $52 \mathrm{kNs} / \mathrm{m}$ ), and $M_{\mathrm{t}}$ is the equivalent track mass $(\mathrm{kg})$ (nominally $133 \mathrm{~kg}$ ).

From Eq. (3), the magnitude of the $P_{2}$ force is linearly proportional to the dip angle regardless of the dip length. Figure $7 \mathrm{~b}$ and $\mathrm{c}$ shows the dynamic wheel forces $\left(P_{2}\right.$ forces are from their low-pass filtering) and axle box accelerations. It can be seen that their magnitudes are related to the dip angles regardless of the dip length, but their frequencies are not related to either dip angles or dip lengths. 

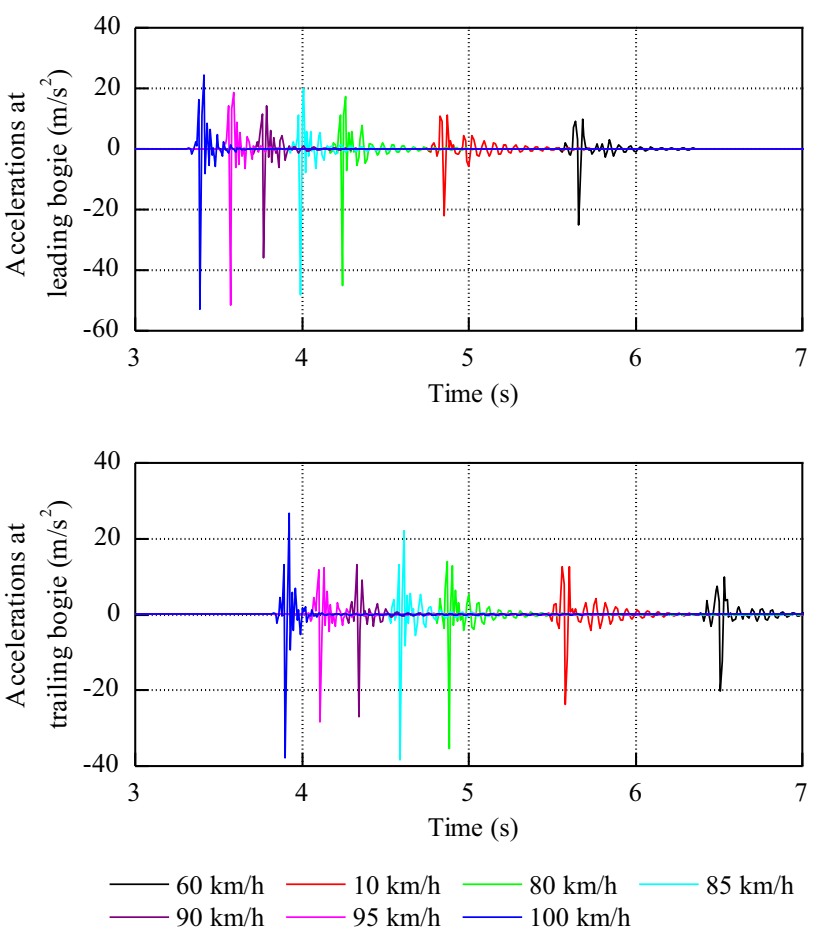

Fig. 8 Accelerations due to dip angle of $0.01 \mathrm{rad}$ at various speeds

Therefore, the relationship between the accelerations on a locomotive component and the dip angles of dipped rail defects is important for monitoring the development of those defects.

Simulations are carried out to determine the relationship between the acceleration values and the locomotive speeds when traversing a dipped rail defect with a fixed dip angle. Simulation parameters include a dip defect with dip angle of $0.01 \mathrm{rad}$ and length of $1 \mathrm{~m}$, with the locomotive passing through this defect at the speeds of $60,7080,85,90,95$ and $100 \mathrm{~km} / \mathrm{h}$. The accelerations at the axle boxes of the middle wheelsets of both bogies are plotted in Fig. 8 .

From Fig. 8, it can be seen that the accelerations are basically consistent on both bogies. In order to establish the relationship between the acceleration values and the locomotive speeds, the acceleration value is taken as the average of peak-peak accelerations on the axle boxes of both middle wheelsets.

These acceleration values are shown in Fig. 9 where it can be seen that the relationship is not linear. At the speed of $85 \mathrm{~km} / \mathrm{h}$, the peak-peak accelerations reach their first maximum values. The simulation results are in conflict with the $P_{2}$ force equation [18] in which track $P_{2}$ force has a linear relationship with the rail vehicle speed.

When the locomotive passes over a dipped joint defect with length $L$, the wheelset's passing frequency $f$ could be calculated from Eq. (4):

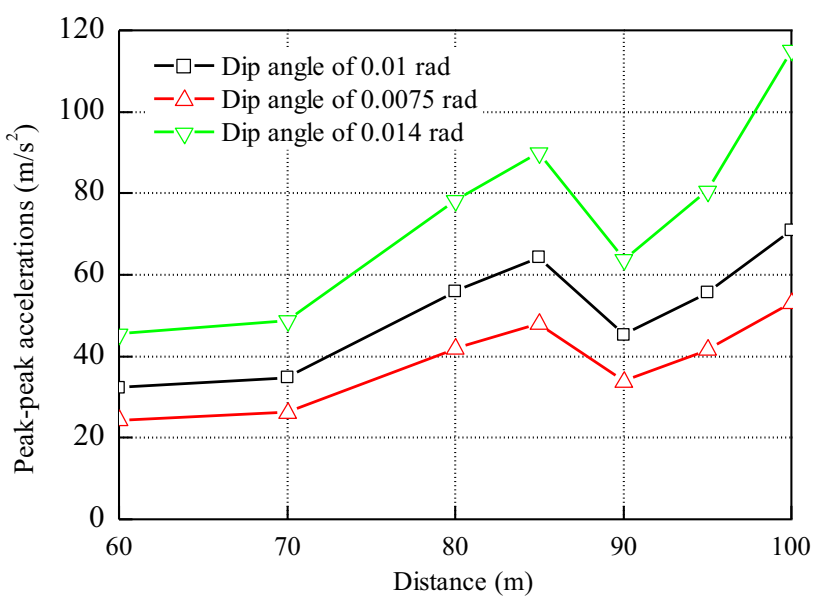

Fig. 9 Average of peak-peak acceleration vs. speed

$f=\frac{v}{3.6 L}$,

where $v$ is the locomotive speed. For speeds of 80,85 and $90 \mathrm{~km} / \mathrm{h}$ and the length $L$ of $1 \mathrm{~m}$, the wheelset's passing frequencies will be 22.22, 23.61 and $25 \mathrm{~Hz}$, respectively. In the locomotive model, the vertical stiffness of the primary suspension is $24 \mathrm{MN} / \mathrm{m}$ and wheelset mass is $2231 \mathrm{~kg}$; hence, the wheelset's theoretical vertical natural frequency $\left(f_{\mathrm{w}}\right)$ without the consideration of damping will be

$f_{\mathrm{w}}=\frac{1}{2 \pi} \sqrt{\frac{2 K_{\mathrm{p} z}}{m_{\mathrm{w}}}}=23.345 \mathrm{~Hz}$,
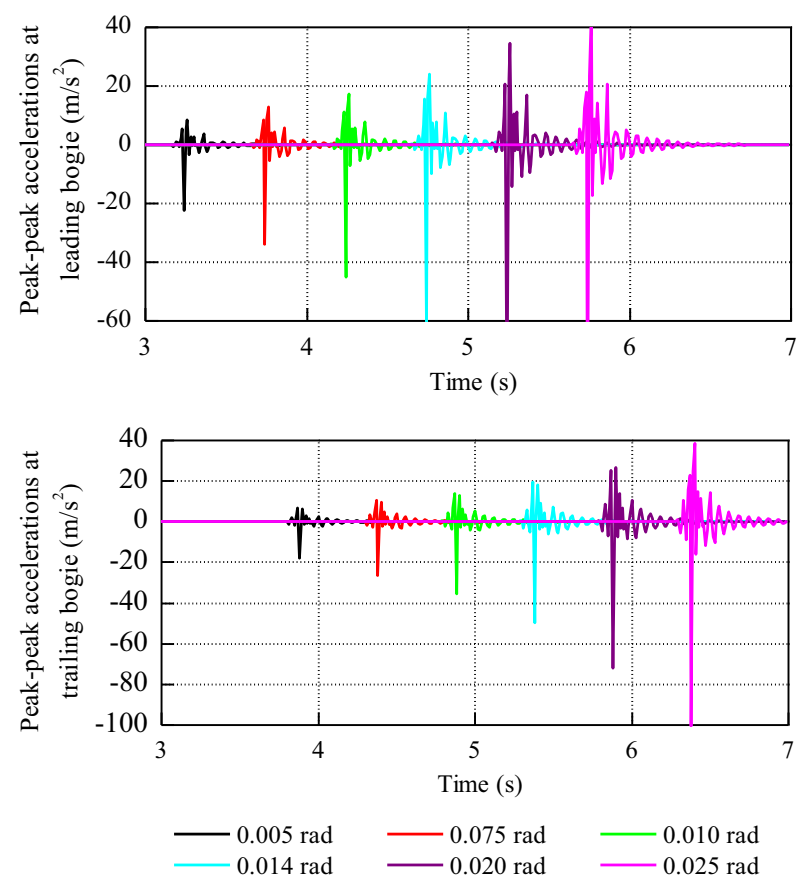

Fig. 10 Accelerations due to various dipped rail defects at speed of $80 \mathrm{~km} / \mathrm{h}$ 


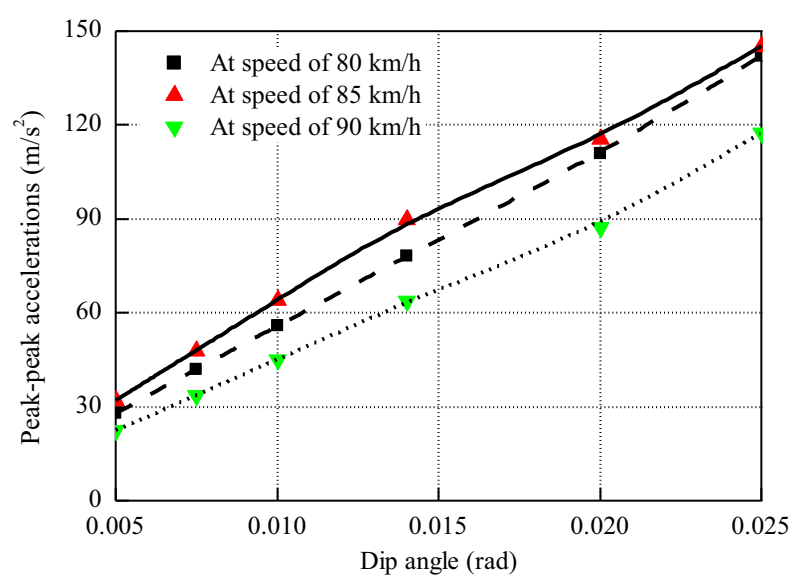

Fig. 11 Average of peak-peak acceleration vs. dip angle

where $K_{\mathrm{p} z}$ is the vertical stiffness of the primary suspension and $m_{\mathrm{w}}$ is the wheelset mass. The above frequency is close to the wheelset's passing frequency of $23.61 \mathrm{~Hz}$ when the speed is $85 \mathrm{~km} / \mathrm{h}$, causing the local resonance. Therefore, at the speed of $85 \mathrm{~km} / \mathrm{h}$, the peak-peak accelerations reach their first maximum values.

The relationship between the acceleration values and various dip angles at known speeds must also be determined. The simulations are carried out at constant speeds of 80,85 and $90 \mathrm{~km} / \mathrm{h}$ with the locomotive passing through several dipped rail defects with dip angles of $0.005,0.075$, $0.01,0.014,0.02$ and 0.025 radians and all with the same length of $1 \mathrm{~m}$. The accelerations at axle boxes of the middle wheelsets of both bogies at a speed of $80 \mathrm{~km} / \mathrm{h}$ are plotted in Fig. 10.

The average of peak-peak accelerations on the axle boxes of both middle wheelsets at speeds of 80,85 and $90 \mathrm{~km} / \mathrm{h}$ is plotted against the dip angles in Fig. 11. It can be seen that the acceleration values generally have a linear relationship with the dip angles, which is consistent with the $P_{2}$ force equation [18], in which the $P_{2}$ force has a linear relationship with the dip angle. It can be seen from Fig. 11 that the acceleration values at a speed of $90 \mathrm{~km} / \mathrm{h}$ are smaller than those at speeds of 80 and $85 \mathrm{~km} / \mathrm{h}$, and the maximum values occur at a speed of $85 \mathrm{~km} / \mathrm{h}$.

In Fig. 11, the minimum acceleration value at the speed of $90 \mathrm{~km} / \mathrm{h}$ is about $20 \mathrm{~m} / \mathrm{s}^{2}$ for a dip angle of $0.005 \mathrm{rad}$, which could be measured by standard accelerometers. To answer the question of how small a dip angle can be monitored, the last simulation is conducted for a dip angle of $0.001 \mathrm{rad}$ with $1 \mathrm{~m}$ wavelength and a speed of $80 \mathrm{~km} / \mathrm{h}$. Therefore, the dip depth at the middle of a $1 \mathrm{~m}$ wavelength dip defect is only about $0.32 \mathrm{~mm}$. The simulated accelerations at the axle boxes of the middle wheelsets of both bogies are shown in Fig. 12. These acceleration values

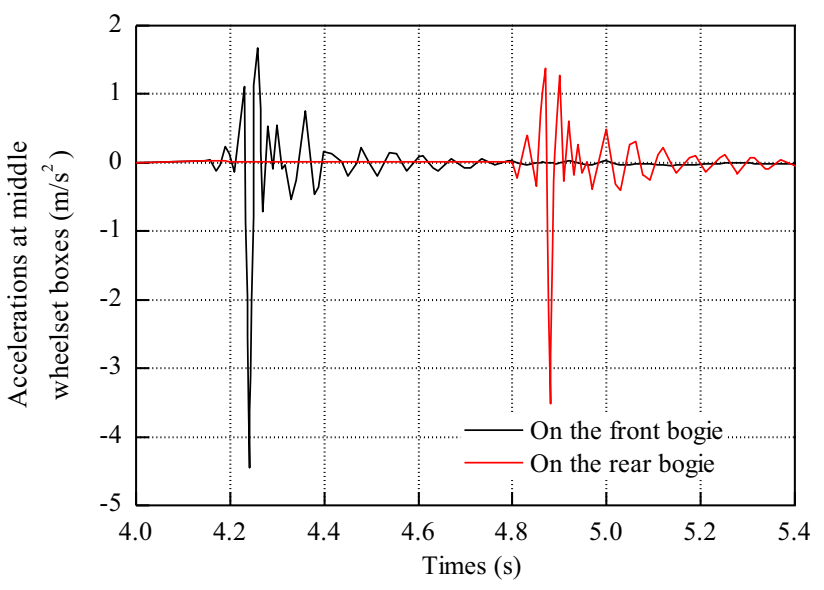

Fig. 12 Accelerations at dip angle of $0.001 \mathrm{rad}$

should be able to be captured by any standard accelerometer.

\section{Discussion and closing remarks}

Through the foregoing discussion of simulations and analysis, it can be concluded that it is possible to monitor short-wavelength rail defects such as dipped rail joints, dipped welds and squats by using a locomotive-mounted acceleration system. The vertical accelerations at a wheelset axle box are sensitive to wheelset dynamic responses due to relatively small defects, e.g. the dip defect with a dip angle of $0.001 \mathrm{rad}$ and $1 \mathrm{~m}$ wavelength.

In the implementation of real operational monitoring, several dip angle threshold values (e.g. 0.01 or $0.014 \mathrm{rad}$ ) should be set so that the railway operators can decide appropriate operational speed settings or decide when remedial track maintenance could be carried out.

The detailed locomotive model is considered to be reliable for several reasons. Firstly, it has been generated based on the GENSYSMBS software package which was validated during the Manchester Benchmark tests [27] and is now widely endorsed by the global railway industry. Furthermore, the modelling of locomotives of this type has been verified by experimental data available to the authors $[23,28,29]$, but which are confidential and currently only available for internal use. Therefore, based on the acceleration measurements, the real dip angles of dipped rail defects can be approximately determined, which will be helpful for future rail maintenance decision making.

Acknowledgements The authors acknowledge the support of the Centre for Railway Engineering, Central Queensland University and the support from State Key Laboratory of Traction Power, Southwest Jiaotong University in the Open Projects: TPL1504, 'Study on heavy haul train and coupler system dynamics'. The authors also 
acknowledge DEsolver for use of the GENSYS software in vehicle dynamics simulation.

Open Access This article is distributed under the terms of the Creative Commons Attribution 4.0 International License (http:// creativecommons.org/licenses/by/4.0/), which permits unrestricted use, distribution, and reproduction in any medium, provided you give appropriate credit to the original author(s) and the source, provide a link to the Creative Commons license, and indicate if changes were made.

\section{References}

1. Malcolm K, Andrew W, Stephen M (2008) The epidemiology of squats and related defects. In: Conference on Railway Engineering (2008: Perth, W.A.). CORE 2008: Rail; The Core of Integrated Transport. Perth: Railway Technical Society of Australasia: Engineers Australia, pp 83-96

2. Oregui M, Li S, Núñez A, Li Z, Carroll R, Dollevoet R (2016) Monitoring bolt tightness of rail joints using axle box acceleration Measurements. In: Struct. Control Health Monit. (2016) Published online in Wiley Online Library (wileyonlinelibrary.com). https://doi.org/10.1002/stc. 1848

3. Mutton PJ, Alvarez EF (2004) Failure modes in aluminothermic rail welds under high axle load conditions. Eng Fail Anal 11:151-166

4. Zerbst U, Lundén R, Edel K-O, Smith RA (2009) Introduction to the damage tolerance behaviour of railway rails. Eng Fract Mech 76(2009):2563-2601

5. Molodova M, Li Z, Dollevoet R (2011) Axle box acceleration: measurement and simulation for detection of short track defects. Wear 271:349-356

6. Molodova M, Li Z, Núñez A, Dollevoet R (2014) Automatic Detection of Squats in Railway Infrastructure. In: IEEE Transactions on Intelligent Transportation Systems, 15(5)

7. Wang C, Xiao Q, Liang H, Liu Y, Cai X (2006) On-line monitoring of railway deformation using acceleration measurement. In: Proceedings of the 6th World Congress on Intelligent Control and Automation, 21-23, 2006, Dalian, China

8. Chiacchiari L, Loprencipe G (2015) Measurement methods and analysis tools for rail irregularities: a case study for urban tram track. J Modern Transp 23(2):137-147

9. Sun YQ, Cole C, McClanachan M, Wilson A, Kaewunruen S, Kerr MB (2009) Rail short-wavelength irregularity identification based on wheel-rail impact response measurements and simulations. In: International Heavy Haul Conference 2009-Shanghai, China

10. Bocciolone M, Caprioli A, Cigada A, Collina A (2007) A measurement system for quick rail inspection and effective track maintenance strategy. Mech Syst Signal Process 21:1242-1254

11. Belotti V, Crenna F, Michelini RC, Rossi GB (2006) Wheel-flat diagnostic tool via wavelet transform. Mech Syst Signal Process 20(2006):1953-1966

12. Zumpano G, Meo M (2006) A new damage detection technique based on wave propagation for rails. Int $\mathrm{J}$ Solids Struct 43:1023-1046
13. Rose JL, Avioli MJ, Mudge P, Sanderson R (2004) Guided wave inspection potential of defects in rail. NDT\&E International 37:153-161

14. Berggren E, Li MXD, Spännar J (2008) A new approach to the analysis and presentation of vertical track geometry quality and rail roughness. Wear 265:1488-1496

15. Spiryagin M, Sun YQ, Cole C, Simson S, Persson I (2011) Development of traction control for hauling locomotives. J Syst Des Dyn 5(6):1214-1225

16. Spiryagin M, Sun YQ, Cole C, McSweeney T, Simson S, Persson I (2013) Development of a real-time bogie test rig model based on railway specialised multibody software. Vehicle Syst Dyn 51(2):236-250

17. Spiryagin M, Cole C, Sun Y (2014) Adhesion estimation and its implementation for traction control of locomotives. Int J Rail Transp 1(2:3):187-204

18. Jenkins HH, Stephenson JE, Clayton GA, Morland GW, Lyon D (1974) The effect of track and vehicle parameters on wheel/rail vertical dynamic forces. Railway Eng. J 3(1):2-16

19. Kabo E, Nielsen JCO, Ekberg A (2006) Prediction of dynamic train-track interaction and subsequent material deterioration in the presence of insulated rail joints. Vehicle Syst Dyn 44(Supplement):718-729

20. Nirmal M, Manicka D, Sun YQ (2016) Impact forces at dipped rail joints. Procee Inst Mech Eng Part F: J Rail Rapid Transit 230(1):271-282

21. Sun YQ, Cole C, Spiryagin M (2013) Study on track dynamic forces due to rail short-wavelength dip defects using rail vehicletrack dynamics simulations. J Mech Sci Technol 27(3):629-640

22. Spiryagin M, Cole C, Sun YQ, McClanachan M, Spiryagin V, McSweeney T (2014) Design and simulation of rail vehicles. Ground Vehicle Engineering Series, CRC Press Taylor \& Francis Group, USA

23. Spiryagin M, Wolfs P, Cole C, Spiryagin V, Sun YQ, McSweeney $T$ (2016) Design and simulation of heavy haul locomotives and trains. Ground Vehicle Engineering Series, CRC Press Taylor \& Francis Group, USA

24. Zhai W (1996) Locomotive-and-track system coupling dynamics and its application to the study of locomotive performance. J China Rail Sci 17(2):58-73 (in Chinese)

25. Sun YQ, Dhanasekar M (2002) A dynamic model for the vertical interaction of rail track and wagon system. Int J Solids Struct 39:1337-1359

26. Iwnicki S (1998) Manchester benchmarks for rail vehicle simulation, Vehicle System Dynamics. 30(3-4):295-313

27. CRC for Rail Innovation, Australia (2008) Measurement and assessment systems for track short-pitch irregularities and crossing geometry irregularities. Project No.: AT-9

28. Spiryagin M, George A, Sun YQ, Cole C, McSweeney T, Simson $S$ (2013) Investigation on the locomotive multibody modelling issues and results assessment based on the locomotive model acceptance procedure. J Rail Rapid Transit 227(5):453-468

29. Spiryagin M, Wolfs P, Szanto F, Cole C (2015) Simplified and advanced modelling of traction control systems of heavy-haul locomotives. Vehicle Syst Dyn 53(5):672-691 